\title{
The effects of total laser pubic hair removal on sexual functions, body perception and self-esteem in women
}

\author{
Mustafa Murat Aydos ${ }^{1 \oplus,}$, Sinay Önen² $\odot$, Efe Önen ${ }^{1} \odot$ \\ ${ }^{1}$ Department of Urology, University of Health Sciences, Bursa Yüksek Ihtisas Training and Research Hospital, Bursa, Turkey \\ ${ }^{2}$ Department of Psychiatry, University of Health Sciences, Bursa Yüksek Ihtisas Training and Research Hospital, Bursa, Turkey
}

\section{ABSTRACT}

Objectives: Both males and females carried out pubic hair removal by various methods usually for visual/aesthetic or psychosexual reasons. The aim of the present study was to evaluate self-esteem, body image and sexual functions of women before and after total laser pubic hair removal (TLPHR) which is frequently being prefered due to its long-lasting effects.

Methods: A total of 45 sexually active women between 20 and 50 years of age who underwent total laser pubic hair removal were included in the study. The sociodemographic features, Female Sexual Function Index (FSFI), Rosenberg Self Esteem Scale (RSES), Body Cathexis Scale (BCS), Beck Depression Inventory (BDI) of the participants were assessed before the first session and after the 6th session of TLPHR procedure.

Results: Total RSES, total BCS scores and the 40th item of the BCS score significantly decreased after the TLPHR procedure $(p<0.001)$. Total FSFI scores and also FSFI subscales of desire, arousal, lubrication and satisfaction scores were significantly increased after TLPHR $(p<0.001)$.

Conclusion: Our study results demonstrated that self-esteem, genital and total body image, sexual desire, sexual arousal and sexual satisfaction was improved after TLPHR procedure. Wider sampled studies examining the effects of laser pubic hair removal on individual, relational and psychosocial issues in both males and females are needed.

Keywords: Pubic, Rosenberg, hair removal, self-estem, laser

$\mathrm{B}$ oth males and females carried out pubic hair removal for many reasons for over the centuries. Modern pubic hair removal is often done for visual/aesthetic or psychosexual reasons rather than for health reasons. [1]. Women are willing to remove their pubic hair for the reasons like hygiene, sexual attractiveness, sexual enhancement, religious-social beliefs and before any gynecological examination $[2,3]$. Also by removing pubic hair women are found to have higher levels of body shame, self consciousness and self objectification [4]. In addition to this some researches proposes males prefer sexual partners to be hairless [5]. Anecdotal reports indicate that pubic hair removal provide increased aesthetic appearance and increased tactile sensitivity of the genitals such as the clitoris, but unfortunately there is insufficient scientific data to support this view [1]. Moreover, unwanted hair loss might be an extremely distressing condition and might cause reduction of self-esteem, well-being and sexuality which was previously demonstrated in women treated for breast cancer and women with hypotrichosis $[6,7]$.

razor blade, waxing, plucking, bleaching, depilatory creams, electrolysis, laser therapy are the most

How to cite this article: Aydos MM, Önen S, Önen E. The effects of total laser pubic hair removal on sexual functions, body perception and self-esteem in women. Eur Res J 2020;6(3):204-209. DOI: 10.18621/eurj.513297

Address for correspondence: Efe Önen, MD., University of Health Sciences, Bursa Yüksek Ihtisas Training and Research Hospital, Department of Urology, Mimar Sinan Mah., Emniyet Cad., Ylldırım, 16310 Bursa, Turkey.E-mail: drefeonen@gmail.com, Fax: +902243660416 
known methods for pubic hair removal [2]. Shaving and waxing are the most common methods of genital hair removal wherefore they are cheap and easy to applicate. Because of avoiding frequent side effects and having longer persistence, the number of women who prefer laser depilation is increasing nowadays. Not only pubic hair removal is recommended by Islam as a tradition of hygiene, but also total pubic hair removal performed to put forth femininity for sexuality in Turkish population [8]. Although in many countries the number of women who have genital grooming is increasing, total pubic hair removal is still the most preferred modality in our country for these reasons.

In several studies, sexual intercourse and sexual satisfaction frequency correlated with total pubic hair removal, particularly in young women. This practice has an interesting psychosexual basis that has not yet been fully explored in sexual medicine. The aim of the present study was to compare self-esteem, body image and sexual functions of women before and after total laser pubic hair removal (TLPHR) procedure.

\section{METHODS}

The present cross-sectional study comprised of 45 women who underwent laser depilation for pubic hair removal between June 2018 and Nowember 2018 at a referral private clinic and our clinic. Sexually active women between 20 and 50 years of age who volunteered to participate and did not have any psychiatric diagnosis were included in the study. Ethics committee approval was obtained from the local ethics committee of Bursa Yuksek Ihtisas Training and Research Hospital (ID:2011-KAEK-25 2018/06-15). And all the women gave written consent, were seen by a doctor at entry to the study.

Participants were asked to fill in self-administered questionnaires before and after the laser depilation sessions. Laser depilation sessions was performed by a $755 \mathrm{~nm}$ diode laser once a month. Participants fulfilled the Female Sexual Function Index (FSFI), Rosenberg Self Esteem Scale (RSES), Body Cathexis Scale (BCS), Beck Depression Inventory (BDI) before the first session and after the 6th session of TLPHR procedure. BMI was calculated by dividing weight (in kilograms) by height (in meters squared). Since increased body weight and depressive disorder may affect self-esteem, body image and sexual functioning, women with a BMI below 18.5 and above 25 and with a BDI score above 17 were excluded from the study.

\section{Instruments}

\section{Sociodemographic Data Form}

This form was developed by the researchers and contained questions directed at determining the women's sociodemographic characteristics including age, height, weight, marital status, education level, occupation, economic status, medical illness, smoking status, alcohol and drug use.

\section{Female Sexual Function Index (FSFI)}

FSFI questionnaire was created by Rosen et al. for the assessment of female sexual functioning [9]. The instrument was validated and adapted to Turkish population by Öksüz and Malhan [10]. Based on clinical interpretations of a principal components analysis, a 6-domain structure was identified including sexual desire, arousal, lubrication, orgasm, satisfaction, and pain. Participants completed the instrument by choosing the option that best described their situation. Each question was associated with a value corresponding to the degree of gratification of the participant. A score of ' 0 ' indicates no sexual activity in the last four weeks, and the others are numbered from 1 to 5 on an incremental scale.

\section{Rosenberg Self-Esteem Scale (RSES)}

RSES is a 10-item likert type scale which was developed by Morris Rosenberg in 1965 to evaluate global self-worth by measuring both positive and negative feelings about one's self [11]. In our country, reliability and validity studies of the scale were performed by Korkmaz [12]. The score received from the first 10 items is evaluated as high self-esteem for a total score of $0-1$, average self-esteem for a total score from 2-4, and low for 5-6. Lower scores indicate higher levels of self-esteem [12].

\section{The Body Cathexis Scale (BCS)}

It is a 40 -item scale which was developed by Secord and Jourand in 1953 to measure the level of body satisfaction and attitude to body image [13]. The reliability and validity of Turkish version was performed by Hovardaoğlu and Özdemir in 1990 [14]. The items are in a 5-point likert type scale that ranges 
from $1=\mathrm{I}$ don't like at all to $5=\mathrm{I}$ really like. The lowest possible score from the scale is 40 and the highest is 200 and higher scores indicate less satisfaction from the body parts. The Cronbach alpha coefficient obtained from this tool in our study was determined to be 0.85 .

\section{Beck Depression Inventory (BDI)}

BDI is a self-report scale consisting of 21 items which is used to evaluate physical, emotional, cognitive and motivational symptoms of depression [15]. Validity and reliability of Turkish version of BDI was performed by Hisli Şahin [16]. The total score vary between $0-63$, and the cut-off value is accepted as 17.

\section{Statistical Analysis}

Statistical analysis was performed using SPSS for Windows version 20.0 (SPSS Inc., Chicago, IL, USA). The data were analyzed for normal distribution of continuous variables using histograms and the Shapiro-Wilk test. The normally distributed continuous variables were reported as mean \pm standard deviation (SD). Categorical variables were reported as frequencies and percentages. To examine the differences between before and after the laser procedure, the continuous covariates were analyzed based on paired samples t test and Wilcoxon signedrank tests.

\section{RESULTS}

The mean age of the study group was $34.1 \pm 4.3$ years. Thirty-seven $(82.2 \%)$ women were employed and $31(68.9 \%)$ women had high education level. All women were heterosexual and sexually active with a partner. Thirty-five $(77.8 \%)$ women were married and $7(15.6 \%)$ were single. The mean BMI of the study group was $21.9 \pm 2.8 \mathrm{~kg} / \mathrm{m} 2$. The sociodemographic features of the study group is given in Table 1 .

The mean BDI score was $8.9 \pm 4.6$ before the first session of TLPHR and there was no statistically significant change in BDI scores after the procedure $(p>0.05)$. The mean RSES scores of the study group were $2.3 \pm 0.7$ before and $1.4 \pm 0.5$ after TLPHR. The mean RSES change was statistically significantly decreased after the laser sessions $(p<0.001)$. Total
Table 1. Demographic characteristics $(n=45)$

\begin{tabular}{lc}
\hline Age (mean \pm SD) & $\mathbf{3 4} \pm \mathbf{4 . 3}$ \\
\hline Marital Status, $\mathrm{n}(\%)$ & $7(15.6)$ \\
Single & $35(77.8)$ \\
Married & $3(6.6)$ \\
Widowed/Divorced & \\
Education Level, $\mathrm{n}(\%)$ & $4(8.9)$ \\
Literate & $10(22.2)$ \\
\hline Primary School & $15(33.3)$ \\
High School & $16(35.6)$ \\
University & $8(17.8)$ \\
Economic status, $\mathrm{n}(\%)$ & $20(44.4)$ \\
Low & $17(37.8)$ \\
Average & $21.9 \pm 2.8$ \\
\hline High &
\end{tabular}

$\mathrm{BMI}=$ Body mass index

BCS scores were $174.42 \pm 17.32$ before and $15674 \pm$ 16.22 after the procedure $(p<0.001)$. Especially the BCS scale 40th item, which indicates the satisfaction from genital organs, was evaluated separately and statistically significantly decreased score was found after the TLPHR procedure $(p<0.001)$ (Table 2$)$.

The mean total FSFI scores of participants were $26.2 \pm 3.4$ before TLPHR and $32.5 \pm 3.9$ after TLPHR procedure. Total FSFI scores significantly increased after the laser depilation $(p<0.001)$. FSFI subscales of desire, arousal, lubrication and satisfaction scores were significantly increased after TLPHR $(p<0.001)$. The mean scale scores before and after TLPHR procedure are given in Table 3.

\section{DISCUSSION}

The present study evaluated the alteration of selfesteem, body image and sexual functions of women who was applied total laser pubic hair removal. Our study results demonstrated that self-esteem, genital and total body image, sexual desire, sexual arousal and sexual satisfaction of study population was improved after TLPHR procedure.

Regular cleaning and grooming of the pubic hair is an important doctrine in Muslim societies. Thus, the 
Table 2. The FSFI scores of the volunteers before and after the laser hair removal procedure

\begin{tabular}{|c|c|c|c|}
\hline & & Mean \pm SD & p value \\
\hline \multirow[t]{3}{*}{ FSFI total } & & & $<0.001$ \\
\hline & Before TLPHR & $26.2 \pm 3.4$ & \\
\hline & After TLPHR & $32.5 \pm 3.9$ & \\
\hline \multirow[t]{3}{*}{ Desire } & & & $<0.001$ \\
\hline & Before TLPHR & $3.7 \pm 0.4$ & \\
\hline & After TLPHR & $5.2 \pm 0.7$ & \\
\hline \multirow[t]{3}{*}{ Arousal } & & & $<0.001$ \\
\hline & Before TLPHR & $3.9 \pm 0.3$ & \\
\hline & After TLPHR & $5.1 \pm 0.5$ & \\
\hline \multirow[t]{3}{*}{ Lubrication } & & & $<0.001$ \\
\hline & Before TLPHR & $4.5 \pm 0.7$ & \\
\hline & After TLPHR & $5.6 \pm 0.8$ & \\
\hline \multirow[t]{3}{*}{ Orgasm } & & & $>0.05$ \\
\hline & Before TLPHR & $4.1 \pm 0.6$ & \\
\hline & After TLPHR & $5.5 \pm 0.8$ & \\
\hline \multirow[t]{3}{*}{ Satisfaction } & & & $<0.001$ \\
\hline & Before TLPHR & $4.3 \pm 0.7$ & \\
\hline & After TLPHR & $5.4 \pm 1.1$ & \\
\hline \multirow[t]{3}{*}{ Pain } & & & $>0.05$ \\
\hline & Before TLPHR & $5.5 \pm 0.9$ & \\
\hline & After TLPHR & $5.4 \pm 1.2$ & \\
\hline
\end{tabular}

FSFI $=$ Female Sexual Function Index, TLPHR $=$ Total Laser Pubic Hair Removal

Table 3. RSES, BCS, BDI scores before and after the TLPHR procedure

\begin{tabular}{lccc}
\hline & Before TLPHR & After TLPHR & $\boldsymbol{p}$ value \\
\hline RSES total & $2.3 \pm 0.7$ & $1.4 \pm 0.5$ & $<\mathbf{0 . 0 0 1}$ \\
BCS & $174.42 \pm 17.32$ & $156.74 \pm 16.22$ & $<\mathbf{0 . 0 0 1}$ \\
BCS $\left(40^{\text {th }}\right.$ item $)$ & $2.39 \pm 0.25$ & $1.77 \pm 0.14$ & $<\mathbf{0 . 0 0 1}$ \\
BDI & $8.9 \pm 4.6$ & $9.0 \pm 4.8$ & 0.91 \\
\hline
\end{tabular}

Data are show as mean \pm standard deviation. RSES $=$ Rosenberg Self Esteem Scale, BCS $=$ Body Cathexis

Scale, BDI = Beck Depression Inventory, TLPHR $=$ Total laser pubic hair removal

hygiene of the pubic area and to be hair-free before sexual intercourse, is a cultural and religious expectation both for women and their spouses that can affect the sexual functions and marital adjustment of the couple. Muallazaziz et al. [8] reported that laser was the third preferred hair removal method among muslim women according to their study results. Also in a study with a larger Turkish population laser pubic hair removal was indicated to be preferred by $16.8 \%$ of the participants [17]. Although it is not the most commonly used method but the increased tendency to prefer LPHR for pubic hair removal in recent years was the reason for the preference of LPHR method in the present study. 
The study of Sangiorgi et al. [18] showed that Brazilian women who are satisfied with the appearance of their own genitalia have a stronger preference for complete removal of pubic hair. Herbenick et al. [19] indicated similar results in their study with 2451 women. In a study of DeMaria et al. [20] which was carried on with 663 female participants who had been removing pubic hair, it was demonstrated that women who were hair-free had a significantly more positive genital self-image than women with at least some hair on their genitals. In our study there was an improvement in the genital body image of women after total laser pubic hair removal (TLPHR) procedure, supporting previous findings.

Hirsutism is defined in females as male type terminal hair growth and distribution occurring in approximately $60 \%$ of cases with Polycystic Ovary Syndrome (PCOS) [21, 22]. Previous studies have reported that women who have PCOS are more prone to depression, anxiety and have lower self-esteem, negative body image, and psychosexual dysfunction [23, 24]. Clayton et al. [25] evaluated the impact of laser hair removal among hirsute women with PCOS and suggested that laser treatment reduced the severity of facial hair, depression and anxiety and improved quality of life over the 6-month study period. Our study results support the previous findings that the decrease of unwanted body hair provide an improvement in body image and sexual functions, and result in an increase in the one's self-esteem.

In a study of Herbenick et al. [19] 2451 women between the ages of 18-65 were compared in terms of pubic hair removal type and sexual dysfunction, and found that women who had done total pubic hair removal had higher scores of total FSFI, desire, arousal, lubrication, pain and sexual satisfaction than women with no hair removal and partial hair removal. Also Bercaw-Pratt et al. [26] point to association between complete depilation and greater sexual activity. According to our study results, total FSFI score and desire, arousal, lubrication and satisfaction subscale scores were significantly increased after TLPHR compared to baseline scores. These findings show that there is a prominent improvement in both sexual functions and sexual satisfaction of the participants after TLPHR procedure. The increase in both sexual desire and sexual arousal might be attributed to the previous asseverations claiming that pubic hair removal provide increased aesthetic appearance and increased tactile sensitivity of the clitoris.

A study of DeMaria et al. [2] revealed that there was no significant differences between body esteem scores among low-income Hispanic, Black, and White women who were current groomers compared to those who were not [2]. In contrary our findings indicate an improvement in the body image and satisfaction in women after total laser pubic hair removal (TLPHR) procedure. This contradiction between the results of the studies can be attributed to the fact that the participants in our study have higher income levels, and increased economic status may be related to the more importance given to the body image and the increase in expectations on aesthetic issues.

\section{Limitations}

This study had several limitations. First, it was limited to $\mathrm{mid} /$ high-income women seeking at our clinic in the Bursa region and therefore studying in wider groups could provide more effective results. The cohort of this study could be accepted as a representation of a Muslim society; thus, our findings may not be generalized to other religious, ethnic and cultural populations.

\section{CONCLUSION}

The present study findings indicate that body satisfaction, self-esteem and sexual functions improve after total laser pubic hair removal in women. The results of the study will be valuable for future studies investigating psychosocial-sociocultural effects of pubic hair removal such as quality of life, psychosocial functionality and marital adjustment. Also more studies with larger groups of patients are required about this topic.

\section{Conflict of interest}

The authors disclosed no conflict of interest during the preparation or publication of this manuscript.

\section{Financing}

The authors disclosed that they did not receive any grant during conduction or writing of this study. 


\section{REFERENCES}

1. Ramsey S, Sweeney C, Fraser M, Oades G. Pubic hair and sexuality: a review. J Sex Med 2009;6:2102-10.

2. DeMaria AL, Berenson AB. Prevalence and correlates of pubic hair grooming among low-income Hispanic, black, and white women. Body Image 2013;10:226-31.

3. Braun V, Tricklebank G, Clarke V. “It shouldn't stick out from your bikini at the beach": Meaning, gender, and the hairy/hairless body. Psychol Women Q 2013;37:478-93.

4. Smolak L, Murnen SK. Gender, self-objectification and pubic hair removal. Sex Roles 2011;65:506-17.

5. Butler S, Smith NK, Collazo E, Caltabiano L, Herbenick D. Pubic hair preferences, reasons for removal and associated genital symptoms: comparisons between men and women. Sex Med 2014;12:48-58.

6. Freedman TG. Social and cultural dimensions of hair loss in women treated for breast cancer. Cancer Nurs 1994;17:334-41. 7. Lee YR, Lee SJ, Kim JC, Ogawa H. Hair restoration surgery in patients with pubic atrichosis or hypotrichosis: review of technique and clinical consideration of 507 cases. Dermatol Surg 2006;32:1327-35.

8. Muallaaziz D, Yayci E, Ataçağ T, Kaptanoğlu AF. Pubic hair removal practices in Muslim women. Basic Clin Sci 2014;3:3944.

9. Rosen R, Brown C, Heiman J, Leiblum S, Meston C, Shabsigh $\mathrm{R}$, et al. The female sexual function index (FSFI): a multidimensional self-report instrument for the assessment of female sexual function. J Sex Marital Ther 2000;26:191-208.

10. Öksüz E, Malhan S. [Reliability and validity of the Female Sexual Function Index in Turkish population]. Sendrom 2005;17:54-60. [Article in Turkish]

11. Rosenberg M. The association between self-esteem and anxiety. J Psychiatr Res 1962;1:135-52.

12. Korkmaz M. Yetişkin örneklem için bir benlik saygısı ölçeğinin güvenirlik ve geçerlik çalışması. (Yayımlanmış yüksek lisans tezi). İzmir: Ege Üniversitesi Sosyal Bilimler Enstitüsü, 1996.

13. Secord PF, Jourand SM. The appraisal of body-cathexis and the self. J Consult Psychol 1953;17:343-7.

14. Hovardaoğlu S, Özdemir YD. Vücut Algısı Ölçeği'nin güvenirlik ve geçerlik çalışması/ Şizofrenik ve major depresif hastaların beden imgelerinden doyum düzeyleri (Yayımlanmamış yüksek lisans tezi). Ankara: Gazi Üniversitesi Sosyal Bilimler Enstitüsü, 1990.
15. Beck AT, Ward CH, Mendelson M, Mock J, Erbaugh J. An inventory for measuring depression. Arch Gen Psychiatry 1961;4:561-71.

16. Hisli Şahin N. Beck depresyon Envanterinin geçerliği üzerine bir çalışma. Psikoloji Dergisi 1988;6:118-26.

17. Kutlubay Z. Alexandrite laser hair removal results in 2359 patients: a Turkish experience. J Cosmet Laser Ther 2009;11:8593.

18. Sangiorgi MLPO, Lara LADS, Lerri MR, Ferriani RA, Romão APMS. The Preference of Women and Men Regarding Female Genital Depilation. Rev Bras Ginecol Obstet 2017;39:488-95.

19. Herbenick D, Schick V, Reece M, Sanders S, Fortenberry JD. Pubic hair removal among women in the United States: prevalence, methods, and characteristics. J Sex Med 2010;7:3322-30.

20. DeMaria AL, Sundstrom B, McInnis SM, Rogers E. Perceptions and correlates of pubic hair removal and grooming among college-aged women: a mixed methods approach. Sexual Health 2016;13:248-56.

21. Norman RJ, Dewailly D, Legro RS, Hickey TE. Polycystic ovary syndrome. Lancet 2007;370:685-97.

22. Azziz R, Carmina E, Dewailly D, Diamanti-Kandarakis E, Escobar-Morreale HF, Futterweit W, et al. Androgen Excess Society: Position statement: criteria for defining polycystic ovary syndrome as a predominantly hyperandrogenic syndrome: an Androgen Excess Society guideline. J Clin Endocrinol Metab 2006;91:4237-45.

23. Coffey S, Mason H. The effect of polycystic ovary syndrome on health related quality of life. Gynecol Endocrinol 2003; 17:379-86.

24. Deeks A, Gibson-Helm M, Teede H. Anxiety and depression in polycystic ovary syndrome (PCOS): a comprehensive investigation. Fertil Steril 2010;93:2421-3.

25. Clayton WJ, Lipton M, Elford J, Rustin M, Sherr L. A randomized controlled trial of laser treatment among hirsute women with polycystic ovary syndrome. $\mathrm{Br} \mathrm{J}$ Dermatol 2005;152:986-92.

26. Bercaw-Pratt JL, Santos XM, Sanchez J, Ayensu-Coker L, Nebgen DR, Dietrich JE. The incidence, attitudes and practices of the removal of pubic hair as a body modification. J Pediatr Adolesc Gynecol 2012;25:12-4. 